throat in some being whitish, in others black. The bird now obtained from Tuskar Rock displays the latter character in its plumage, and is indeed the black-throated wheatear (Saxicola stapazina) of earlier writers. When I find time to compare it I hope to be able to assign it to its racial form. In the meantime it seems desirable to announce its occurrence without delay as a bird quite new to Ireland. I have to express my great gratitude to $\mathrm{Mr}$. Glanville for so kindly sending me this interesting specimen in the flesh for identification and investigation.

The University, Sheffield.

\section{EXPERIMENTAL BIOLOGY.}

WE use in our title the term Experimental Biology, which requires some apology, as a convenient label for an interesting bundle of thirteen papers by Jacques Loeb and Hardolph Wasteneys. They give an account of important experiments bearing on a variety of puzzling biological problems. (I) Loeb showed many years ago (1889) that some animals orient themselves in relation to a luminous object so that their plane of symmetry falls into the direction of the rays of light, and suggested that this reaction was comparable to the heliotropic reaction of plants. In 1897 he brought forward evidence in support of the view that the action of light in evoking a heliotropic reaction is chemical, and this theory is now confirmed by additional facts.

According to the law of Bunsen and Roscoe, the photochemical effect of light is equal to the product of the intensity into the duration of illumination, and this has been shown to hold for the heliotropic curvatures of plants (Blaauw and Fröschl) and of hydroids (Loeb and Ewald). Furthermore, it has now been shown by Loeb and Wasteneys that the region in the spectrum most efficient in the production of heliotropic curvature is almost the same for hydroids (Eudendrium) and for oat seedlings. The investigators suggest that there are two types of photosensitive substance, one with a maximum sensitiveness (or absorption) in the yellowish-green, and the other with a maximum of sensitiveness in the blue. The first type is represented by visual purple, and a photosensitive substance of this type. occurs in Chlamydomonas (often claimed as a plant), in Daphnia, and in many other organisms. The second type of photosensitive substance occurs in Euglena, in Eudendrium, and in many plants. Thus the distribution of the type of substance does not correspond to the boundaries between plants and animals.

(2) In another series of experiments Loeb inquires into the conditions which determine or prevent the entrance of the spermatozoon into the egg. It is well known that a fertilised egg is non-receptive to other spermatozoa. What is the nature of this block? It is not due to the changes underlying the development of the egg, for if the eggs of a sea-urchin are induced to develop by the methods of artificial parthenogenesis, a spermatozoon may still enter the egg or an individual blastomere. By simply altering the alkalinity of the sea-water Loeb can make a sea-urchin ovum receptive or non-receptive to the spermatozoon of a starfish; this depends on some rapid alteration of a physical property of the surface of the ovum. And the ingeniously worked-out experimental argument points to the conclusion that a block of this sort is induced when a spermatozoon fertilises an egg.

But what of the more positive side of the question? There is a widespread belief that -a spermatozoon shows a positive chemotropism for the appropriate ovum, but Loeb finds no proof of this in sea-urchins. The motility brings the spermatozoon fortuitously near the egg; the vibrations may assist in boring and in fixing the spermatozoon to the surface of the ovum until other forces, such as surface-tension, come into play. What is certain is that the spermatozoon cannot enter the egg unless physical conditions at the boundaries of egg, spermatozoon, and surrounding solution are right. It must be noted, however, that a sea-urchin spermatozoon becomes more active when it comes near an egg of its own species, and Loeb suggests that this activating effect of the egg upon spermatozoa, being most rapid as regards spermatozoa of its own species, is a means of preventing hybridisation. In other words, the activating influence of the egg has some degree of selective specificity.

(3) In a third set of experiments Loeb tackles the problem of the degenerate condition of the eyes in some cave animals, such as fishes and salamanders. Though a few zoologists cling to the "natural" interpretation that the "blindness," which differs considerably in degree, is due to the hereditary accumulation of the results of disuse, the difficulties in the way of accepting this Lamarckian view are very serious. It has been assumed, therefore, that the blindness of some cave animals began as a germinal variation or mutation. But confidence in the legitimacy of this assumption has been lessened by the meagreness of our knowledge as to the occurrence of variations in the direction of optic degeneration. Very welcome, therefore, are Loeb's recent experiments which show that degeneracy of the eye can be readily induced by influences. affecting the condition of the egg or the earliest stages of development. Thus, embryos with degenerate eyes can be produced by fertilising the eggs of Fundulus heteroclitus with the spermatozoa of Menidia.

Since in these cases there is usually no circulation in the feeble embryos, the inference is suggested that the anomalous condition of the eye may be due to lack of circulation. Blind embryos of the pure breed of Fundulus may be produced by the addition of $\mathrm{KCN}$ to the seawater; and a short exposure of the fertilised ova to temperatures between zero and $2^{\circ} \mathrm{C}$. results in abnormal embryos, a certain percentage of which will show degenerate eyes. It is interesting to learn that lack of light does not, in the case of Fundulus, influence the development of the eye. From Loeb's experiments it is not to be argued that the blindness of cave animals NO. 2433, VOL. 97$]$ 
arose in any of the ways mentioned. What the experiments show is the legitimacy of the assumption that blindness may arise as a germinal variation or factorial mutation. And that is considerable gain.

(4) Other experiments deal with the influence of balanced and non-balanced salt solutions upon the osmotic pressure of the body liquids of Fundulus; with the functional importance of the ratio of concentration of antagonistic salts with univalent and bivalent cations; and with the membrane formation in the eggs of the sea-urchin.

(5) In an illuminating essay on the stimulation of growth, Loeb states his view that it may be inherent in an unfettered cell to grow and divide eternally in appropriate conditions, as is illustrated, indeed, by both Protozoa and Protophytes. This capacity may depend on the presence of synthetic ferments or "synthetic mechanisms" which are formed from the food taken up by the cells. But few cells show this capacity, and the question rises, What stimulates growth and what keeps the cell at rest? In most cases the unfertilised ovum soon dies, in spite of its potential immortality. If it is fertilised or treated with the methods of artificial parthenogenesis, it divides actively. The condition of rest or activity in this case depends, according to Loeb, upon the condition of the cortical layer of the egg and the alteration in the rate of oxidations connected with this condition. We do not know whether the resting of bodycells is determined by conditions identical with those determining rest in the egg.

We know, however, that specific substances circulating in the blood can induce certain resting cells in the body to grow, and that these substances differ apparently for different types of cells. It may be that in the body substances antagonistic to these may enforce the inactivity of the cells.

(6) In a vigorous and characteristic paper entitled "Mechanistic Science and Metaphysical Romance," Loeb argues that the demonstration of the reality of molecules and the counting of their number in a given mass of matter "puts science for a long time, and probably irrevocably, on a mechanistic basis. It marks, perhaps, the greatest epoch in the history of the theory of cognition. It enables and compels us to define the task of science differently from Kirchhoff, Mach, and Ostwald. We may say it is the task of science to visualise completely and correctly the phenomena of nature, of which our senses give us only very fragmentary and disconnected perceptions. We must try to visualise the numerous hidden processes and conditions connecting the disconnected phenomena we perceive." We cannot argue the question here, but we must be allowed to enter our dissent from Loeb's conclusion that the activities, development, and evolution of organisms can be adequately and exhaustively described in mechanical terms, or in chemico-physical terms (which are regarded by many as ideally mechanical). We are convinced that in living creatures new aspects of reality have emerged which transcend NO. 2433, VOL. 97] mechanistic formulation. We are inclined to think that further study of the metaphysics which this consummately ingenious experimenter slangs so vigorously might render him less confident in the stability of his mechanistic system. We yield to none in our admiration of his illuminating scientific achievements, but we cannot agree with his philosophy.

J. A. T.

\section{THE GREAT CANADIAN REFLECTOR.}

VERY satisfactory progress is being made on the great 72 -in. reflecting telescope which is being constructed for the Canadian Government, and is now approaching the final stages of erection and adjusting.

The mounting has been completed by the Warner and Swasey Co., of Cleveland, Ohio, and has been temporarily erected at their factory. Exhaustive tests have shown that the operating mechanism works perfectly. The entire mounting weighs about $\mathrm{r} 20,000 \mathrm{lb}$, of which the moving parts weigh upwards of $80,000 \mathrm{lb}$, and yet it moves with the greatest smoothness and ease. The worm wheel for driving the telescope weighs more than $4000 \mathrm{lb}$, and yet it may be turned readily on its axis with the finger. By means of seven electric motors and conveniently situated stationary and portable switchboards, the instrument can be set, driven, and guided with the utmost facility. Indeed, the immense machine can be operated and handled with greater ease than many small telescopes. The mounting will be taken down and shipped to the observatory as soon as the erection of its dome is sufficiently advanced.

The optical portions of the telescope are being made by the John A. Brashear Co., of Pittsburgh, $\mathrm{Pa}$. The principal part, namely, the great mirror, 73 in. in diameter, is also well advanced. It has been brought to the spherical form, and will be given the paraboloidal form and finally polished as soon as the firm has completed a large plane mirror which is required for testing it. The smaller optical parts are all completed, and have been attached to the mounting. It is hoped that the mirror will be ready as soon as the mounting is erected and in condition to receive it, which will be about the end of the summer.

The pier to support the telescope was completed last autumn. It is made of reinforced concrete, and is of massive construction. The walls of the surrounding circular steel building, $66 \mathrm{ft}$. in diameter, were erected during the winter, and the dome, constructed by the Warner and Swasey Co., which will rest and revolve upon these walls, arrived in Victoria, B.C., about the end of March, and is now being put in place. The shutter opening is $15 \mathrm{ft}$. in width. The dome has been very carefully designed to work in conjunction with the telescope, and it is confidently believed that it will be the most complete and convenient of any in the world.

One of the observers' residences has been erected, but none of the other buildings required have yet been begun. It is hoped, however, that 